\title{
PERCEPÇÃO DE SEGURANÇA E RISCO DE CONTÁGIO POR COVID-19 DURANTES AS VIVÊNCIAS DE LAZER DO RESIDENTE DO RIO GRANDE DO NORTE
}

Recebido em: 10/08/2020

Aprovado em: 01/09/2020

Licença: @) (1) @

\author{
Salete Gonçalves ${ }^{1}$ \\ Rosa Maria Rodrigues Lopes ${ }^{2}$ \\ Michele de Sousa ${ }^{3}$ \\ Mossoró - RN - Brasil
}

Universidade do Estado do Rio Grande do Norte (UERN)

Tatiana Gehlen Marodin ${ }^{4}$

Instituto Federal do Rio Grande do Norte (IFRN)

Natal - RN - Brasil

RESUMO: O artigo tem como objetivo geral compreender a percepção de segurança e risco de contágio por Covid-19 durante as vivências de lazer do residente do Rio Grande do Norte. E do ponto de vista específico, traçar um panorama da pandemia no estado potiguar; analisar o perfil socioeconômico dos pesquisados; identificar os espaços e vivências de lazer com menor risco de contágio no segundo semestre de 2020. Trata-se de um estudo exploratório, com a utilização de dados primários e secundários e amostra não-probabilística. De forma geral, os resultados apontam que os respondentes se sentem mais seguros em desenvolver atividades em áreas naturais e menos seguros em espaços com capacidade de maior aglomeração de pessoas. Por fim, acredita-se que os protocolos de segurança auxiliarão na confiança e retomadas de determinadas vivências de forma lenta e gradual.

PALAVRAS-CHAVE: Atividades de Lazer. Covid-19. Percepção de Segurança e Risco de Contágio.

\section{PERCEPTION OF SECURITY AND RISK OF CONTIGIOUS BY COVID-19 DURING THE LEISURE EXPERIENCES OF THE RESIDENT OF RIO}

\footnotetext{
${ }^{1}$ Docente do Departamento de Turismo Universidade do Estado do Rio Grande do Norte. Doutora em Estudos do Lazer pela UFMG. Pesquisadora do Grupo de Estudos Turísticos (GET) da UERN e do Grupo Ludicidade, Cultura e Educação (LUCE) da UFMG.

${ }^{2}$ Docente do Departamento de Turismo e do Programa de Pós-Graduação em Geografia (PPGeo) da Universidade do Estado do Rio Grande do Norte. Doutora em Geografia pela UFRN. Líder do Grupo de Estudos Turísticos (GET) da UERN. Colaboradora do Centro de Estudos de Geografia e Ordenamento Territorial da Universidade do Porto/Portugal.

${ }^{3}$ Docente do Departamento de Turismo Universidade do Estado do Rio Grande do Norte. Doutora em Geografia pela UNESP. Pesquisadora do Grupo de Estudos Turísticos (GET) da UERN.

${ }^{4}$ Docente dos Cursos de Guia de Turismo e Eventos do Instituto Federal do Rio Grande do Norte (IFRN). Mestre em Administração pela Universidade Potiguar (UNP). Pesquisadora do Grupo de Estudos Turísticos (GET) da UERN.
} 


\section{GRANDE DO NORTE}

ABSTRACT: The article has the general objective to understand the perception of safety and risk of Covid-19 contagion during leisure experiences of Rio Grande do Norte's residents. And from the specific point of view, to outline a panorama of the pandemic in the state of Rio Grande do Norte; to analyze the socioeconomic profile of those surveyed; to identify leisure spaces and experiences with a lower risk of contagion for enjoyment in the second half of 2020. This is an exploratory study, using primary and secondary data and a non-probabilistic sample. In general, the results indicate that respondents feel safer in developing activities in natural areas and less safe in spaces with a greater capacity for gatherings. Finally, it is believed that security protocols will assist in the confidence and resumption of certain leisure experiences in a slow and gradual way.

KEYWORDS: Leisure Activities. Covid-19. Perception of Safety and Risk of Contagion.

\section{Introdução}

A pandemia que hoje redefine o cotidiano das pessoas em suas mais variadas dimensões tem uma história muito recente e que ainda está sendo escrita. Os primeiros casos, datados de dezembro de 2019, na cidade de Wuhan, na China, alertaram para a alta transmissibilidade da doença que ficou conhecida como Covid-19. Em poucos meses, o mundo constatou o poder de contágio do novo coronavírus, e, em 11 de março de 2020, a Organização Mundial da Saúde (OMS) declarou que se tratava de uma pandemia, o que significava que a doença já havia tomado repercussões em escala mundial. Os dados da Organização Pan-americana de Saúde (OPAS) e OMS, de 20 de agosto de 2020, apontam que em oito meses, as estatísticas registraram um número de 22.256.220 de pessoas contaminadas e 782.456 de óbitos em todo mundo (OPAS/OMS, 2020). Até então, o maior país da América do Sul, ainda estava se situando em meio a esse contexto com reflexos mundiais. Foi somente em 20 de março que o Ministério da Saúde, reconheceu em todo Brasil a contaminação comunitária, quando estados como Rio de Janeiro, Minas Gerais, São Paulo, Santa Catarina, Pernambuco e Rio Grande do Sul já haviam decretado (LINDNER, 2020). A partir de então, foram vários os instrumentos de caráter normativo 
que sinalizaram para uma gradual e necessária mudança de vida, de comportamento da população. Alinhados ou não às prerrogativas estabelecidas pelo Governo Federal, os estados federativos se empenharam, conforme as interpretações locais e regionais, em estabelecer as necessárias medidas de isolamento e distanciamento social, com a finalidade de conter esse processo acelerado de contaminação conforme já evidenciado em outros países, especialmente China, Itália e Espanha.

No Rio Grande do Norte não foi diferente. O primeiro instrumento normativo lançado nesse sentido datou de 19 de março (Decreto n. 29.534) quando o estado reconheceu o estado de calamidade pública (RIO GRANDE DO NORTE, 2020a). Os sucessivos decretos indicaram medidas mais rígidas relacionadas a um isolamento social mais intenso em abril e maio. A partir de junho já se falava em maior flexibilização, culminando em normativas mais flexíveis em julho, com a retomada gradual de diversas atividades, sobretudo, as de natureza econômica.

O fato é que nesse espaço de tempo a população viu seu cotidiano ser modificado em diversos aspectos, sendo o isolamento social, o norteador de todos eles. Dentre várias práticas que caracterizam a dinâmica social, as práticas de lazer passaram a sentir os reflexos de todas as medidas restritivas, haja vista o fechamento de diversos espaços de lazer públicos e privados como medida de segurança sanitária para evitar aglomerações. Desse modo, a lógica do lazer, tão necessária à reprodução da vida, teve que experimentar algumas adequações que pudessem ser circunscritas ao ambiente doméstico, seja no sentido de intensificar alguns consumos que já se apresentavam como tendência, seja para passar a considerá-los como prática de lazer. Nesse contexto, faz-se importante destacar o crescimento na adesão de vivências mediadas pelo uso de tecnologias com o suporte de mídias diversas relacionadas às redes sociais (Whatsapp, Instagram, Facebook, Twitter e outros) e plataformas de streaming (Amazon, Netflix Globo Play e outros). 
Consorciado ao desafio de reinterpretar as possibilidades de lazer em uma dinâmica limitada ao espaço doméstico, têm-se outros desafios que acabam por evidenciar a necessidade desses momentos de não trabalho e que também estão circunscritos ao ambiente da casa e refletem as tensões do convívio intenso e por prolongado período de tempo entre os que habitam o mesmo espaço. À título de exemplo vale destacar a desigualdade de gênero que acaba por ratificar uma divisão social do trabalho abusiva, extenuante e violenta para muitas mulheres em seu ambiente doméstico; a gestão das atividades profissionais e educacionais realizadas remotamente em consórcio com as atividades pessoais; as incertezas sobre o futuro próximo ou distante e que estão relacionadas, dentre outros fatores, à manutenção do emprego, à possibilidade da reprodução social de forma digna, mas, em algumas situações, à ocorrência do luto vivido em razão da perda de algum familiar, amigo ou em decorrência do aumento expressivo e acelerado no número de pessoas contaminadas e de óbitos amplamente noticiados diariamente. Além de todos esses elementos não é demais lembrar o conjunto dos reflexos socioeconômicos, sentidos pela sociedade como um todo e que se agravam em realidades onde as desigualdades sociais são mais evidentes, como é o caso do Brasil, gerando ainda mais incertezas.

Nessa perspectiva, o artigo ora apresentado considera toda essa contextualização e objetiva compreender a percepção de segurança e risco de contágio por COVID-19 nas vivências de lazer do residente do Rio Grande do Norte. Para essa construção, do ponto de vista específico, foi preciso traçar um panorama da pandemia no estado potiguar; analisar o perfil socioeconômico dos pesquisados; identificar os espaços e vivências de lazer com menor risco de contágio no segundo semestre de 2020, segundo a percepção dos entrevistados. 
Sua construção está delineada sob uma perspectiva exploratória de investigação que contou com levantamento de informações secundárias (documental e bibliográfica) e de informações primárias, por intermédio de questionário, através do Google Forms. O estudo compõe pesquisa empreendida e institucionalizada por duas Instituições de Ensino Superior - Universidade do Estado do Rio Grande do Norte (UERN) e Instituto Federal do Rio Grande do Norte (IFRN).

O texto está estruturado em partes sequenciadas conforme a seguinte descrição: uma discussão inicial sobre o direito ao lazer e a liberdade frente a Covid-19; seguido pelo percurso metodológico da pesquisa; posteriormente, apresenta-se a discussão dos resultados; e, por fim, algumas considerações frente aos objetivos propostos e proposições para futuras pesquisas, uma vez que o cenário delineado no âmbito da pandemia é circunstancial.

\section{O Direito ao Lazer e à Liberdade de Ir e Vir em Tempos de Pandemia}

O lazer é uma prática social que deve ser contextualizado local e historicamente, pois integra diversas culturas, não se limitando apenas a uma visão compartimentada e tradicional vinculada à sociedade ocidental e industrial (GOMES, 2014b). Mas envolve uma série de manifestações culturais, principalmente diante de um mundo cada vez mais ubíquo, ou seja,

[...] o lazer não se refere apenas ás práticas chamadas tradicionais ou folclóricas, mas também a todo tipo de prática social geralmente considerada como moderna e emergente. Entre elas, por exemplo, podem ser citadas as experiências ligadas à virtualidade, os novos gostos musicais, estilos de festas ou determinadas atividades que para uma pessoa de outra geração ou de outra cultura podem não ser compreendidos ${ }^{5}$ (GOMES, 2014b, p. 364-365).

\footnotetext{
${ }^{5}$ Citação no original: “[...] el ocio no se refiere solamente a las prácticas llamadas tradicionales o folclóricas, sino también a todo tipo de práctica social generalmente considerada como moderna y emergente. Entre ellas, por ejemplo, pueden ser citadas las experiencias ligadas a la virtualidad, los nuevos gustos musicales, estilos de fiestas o determinadas actividades que para una persona de otra generación o de otra cultura pueden no ser comprendidos" (GOMES, 2014b, p. 364-365).
}

licere, Belo Horizonte, v.23, n.3, set/2020. 
Percebe-se assim, que as manifestações culturais que constituem o lazer podem ser das mais diversas formas, dentre elas: a dança, os jogos eletrônicos, a leitura, o esporte, as viagens, as representações artísticas, as manualidades e as práticas corporais. Sendo ressignificado a cada nova geração e contexto social, como resultado da própria dinamicidade da cultura e das sociedades nas quais se vivenciam. Mas independentemente de sociedade ou cultura, o fato é que o lazer é considerado uma necessidade humana (GOMES, 2014a). E embora, sendo uma necessidade humana, algumas sociedades tratam o lazer também como um direito social, sendo garantido pelo Estado através de políticas públicas.

No Brasil, o direito ao lazer surgiu na Constituição Federal (CF) de 1988, pelos artigos $6^{\circ}$ e $227^{\circ}$, como um direito social juntamente com a educação, saúde, moradia, entre outros (BRASIL, 1988). No campo do Direito ele tem o status de direito de $2^{\mathrm{a}}$ geração, datando de conquistas do início do século XX, e são denominados de direitos programáticos, uma vez que são prestações positivas que o Estado precisa pôr em prática e oferecer ao indivíduo. Esta observância dos direitos de $2^{\mathrm{a}}$ geração é obrigatória para o Poder Público. Apesar de o significado em latim da palavra lazer "ser lícito", "ser permitido", o direito ao lazer na verdade se transformou em obrigação legal do Estado e se assim não o fosse poderia ser considerado como uma faculdade do indivíduo e o Poder Público não teria obrigatoriedade de implementá-lo (PIRES, 2012).

Antes da conquista do lazer como direito social, resultado de várias décadas de reinvindicação e de lutas sociais, outro direito que o antecede é o direito à liberdade garantido pelo Art. $5^{\circ}$ caput da CF. O direito de locomoção, de ir e vir sem qualquer restrição desde que não fira nenhum direito alheio, se sobrepõe ao direito ao lazer, por se tratar de um direito de $1^{a}$ geração. Cabe esclarecer que esse direito tem como marco as revoluções liberais do século XVIII e também são chamados de direitos de defesa, pois 
protegem o indivíduo contra intervenções indevidas do Estado, e envolve ainda o direito à vida, à igualdade perante a lei, à propriedade e à intimidade.

Em tempos de pandemia de Covid-19, onde foram instituídas muitas medidas restritivas de circulação e isolamento social, o direito à liberdade é muito invocado por àqueles que não aceitam as medidas de distanciamento social. Porém, é oportuno lembrar que esse é um direito individual e que ele não pode ser interpretado isoladamente. Deve dialogar com outros direitos e valores de igual hierarquia constitucional, como o direito à vida e o direito à saúde.

Neste momento de pandemia, nunca testemunhado no planeta durante este século, é oportuno lembrar que o direito coletivo deve prevalecer em detrimento ao direito individual. Portanto, com o objetivo de reduzir as interações sociais em uma comunidade, o que inclui a circulação de pessoas infectadas, o Estado tem por obrigação adotar medidas de contenção e de enfrentamento, ainda que diminua, excepcionalmente, a liberdade de locomoção (SANTOS, 2020a).

Segundo Aquino et al (2020), países com imensas extensões territoriais como o Brasil e a Índia onde a população é numerosa, há também desigualdades sociais significativas. $\mathrm{O}$ acesso aos recursos de atenção à saúde é muito desigual e a adoção de medidas mais rigorosas de distanciamento social são determinantes para evitar um colapso. Canabarro et al (2020) também confirmam em estudo recente que a manutenção e o fortalecimento das atuais medidas de distanciamento social, isolamento dos casos de contágio e quarentena são absolutamente necessários na realidade brasileira, até por não haver outra solução que possa ser mais efetiva na atualidade.

No caso nacional, os estados e municípios tiveram a sua autonomia reconhecida pelo Supremo Tribunal Federal (STF) para decidir sobre as regras de distanciamento social, tendo em vista o cenário político vivenciado na atualidade uma vez que o Governo 
Federal não foi suficientemente eficaz nas medidas adotadas e deixou a população por muitas vezes mais confusa que esclarecida.

Cada estado adotou medidas que entendeu necessárias e com restrições de acessibilidade de acordo com o avanço da doença em seu território. O Rio Grande do Norte publicou vários decretos, sendo o primeiro no dia 17/03/2020, de $\mathrm{n}^{\circ} 29524$ (RIO GRANDE DO NORTE, 2020b) onde determinou a suspensão das atividades escolares, a suspensão de eventos de massa, shows, atividades desportivas e congêneres com presença de mais de 100 pessoas, feiras, exposições, eventos entre várias outras suspensões e naquele momento recomendou à população que não frequentassem academias, shopping centers, teatros, cinemas e feiras livres com o intuito de evitar aglomerações.

Posteriormente, outros decretos foram sendo publicados, e os níveis de restrição à movimentação das pessoas foi aumentando, à medida em que a transmissibilidade se intensificava, como o fechamento dos shopping centers, restaurantes, bares, casas de espetáculos, teatros, igrejas e templos, diminuição de eventos para 50 pessoas, posteriormente para 20 pessoas e assim por diante.

As praias também foram incluídas nos decretos como pontos de suspensão de atividades, salvo para atividades físicas individuais e com uma série de observações das regras sanitárias. Apesar de constar no Decreto estadual a suspensão do uso coletivo das praias, coube a cada município legislar sobre esse assunto.

Diante dessa nova realidade, causada pela Covid-19, o direito à liberdade individual de locomoção previsto na $\mathrm{CF}$ teve que ceder espaço ao direito coletivo à saúde. Recomendando a população cumprir isolamento social e permanecer em suas residências, como medida de prevenção ao coronavírus e que se evitasse a sua disseminação. Dessa forma, esses decretos impactariam as várias dimensões da vida humana, dentre elas o 
lazer, uma vez que vários espaços, tais como: parques, praias, museus, academias, teatros e cinemas, foram fechados e/ou com muitas restrições para o usufruto do cidadão.

Esse novo modus vivendi interferiu diretamente no lazer da população, tendo em vista que muitas pessoas não puderam sair de suas casas e tiveram que ressignificar, reconfigurar, readaptar e reinventar suas vivências durante a pandemia, considerando tanto a categoria espaço quanto tempo.

Com relação ao espaço, o ambiente doméstico se sobrepôs aos demais, já que, segundo a OMS/OPAS (2020), a melhor forma de controlar os riscos de contágio pelo Coronavírus SARS-CoV-2 é através do isolamento social. Ressalta-se que esse vírus é categorizado como classe de risco 3, o que significa que "apresenta alto risco para a pessoa contaminada e moderado risco para a comunidade" (FIOCRUZ, 2020, s/n), dessa forma, permanecer em casa é uma das principais medidas de prevenção.

$\mathrm{Na}$ residência, as experiências sociais foram ampliadas para o espaço virtual. Nesse ambiente, “também se abre a oportunidade de ressignificação pessoal, de encontro com o outro e de vivências emocionais capazes de promover a similaridade com o ambiente real" (SCHWARTZ; CAMPAGNA, 2006, p. 177).

Sendo possível assim, interagir com os amigos e parentes através da internet e das mídias sociais, com o uso de um celular, smartphone, tablet, computador ou notebook. Utilizando ferramentas e recursos tecnológicos para acessar jogos; assistir a programas de televisão, filmes e/ou séries; ler; ouvir música; realizar atividades corporais; visitar museus e outros equipamentos culturais.

Essa dimensão da virtualidade no lazer está sendo evidenciada durante a pandemia, uma vez que há maior permanência no ambiente doméstico, tanto em atividades passivas quanto ativas. Nesse sentido, é notório o aumento de algumas práticas durante o período pandêmico, dentre elas a procura por práticas corporais feitas em casa, 
com auxílio de aulas virtuais com professores particulares ou sites que oferecem uma gama de exercícios físicos a serem escolhidos pelo usuário, para atestar isso, segundo informativo do site Netshoes, especializado em artigos esportivos, a compra de itens como cordas, colchonetes, halteres e anilhas tiveram um aumento de $2.500 \%$ só no mês de março de 2020 quando tiveram início as medidas de distanciamento social no Brasil (LARGHI, 2020).

Outra prática que se intensificou durante a pandemia foram as lives e videochamadas, segundo pesquisa realizada pela Mobile Time/Opinion Box - Uso de Apps no Brasil (PANORAMA, 2020), com 2.017 brasileiros pesquisados entre 6 e 13 de maio de 2020, com 16 anos ou mais e que possuem smartphone, os resultados demonstraram que $52 \%$ dos entrevistados afirmaram que aumentaram o número de realização de videochamadas desde o início da quarentena; $66 \%$ aumentaram a frequência de visualização de uma transmissão ao vivo (lives) na tela do seu aparelho no período de confinamento em casa. Considerando o período de 12 meses, saltou de 38 para $51 \%$ a proporção de internautas brasileiros que assinam um serviço de streaming de filmes ou séries. A plataforma mais usada para consumo deste conteúdo são YouTube (84\%), seguida por Instagram (54\%) e Facebook (41\%).

Frente a esse aumento do uso dos meios e práticas virtuais, cabe ressaltar que nem todos têm acesso a esse tipo de lazer, devido às grandes desigualdades sociais existentes no país, onde uma parcela significativa da população brasileira não tem acesso à internet e vive em precárias condições de vida. Para esses sujeitos o enfrentamento da pandemia torna-se mais difícil, uma vez que vivem em bairros sem o mínimo de infraestrutura, sem saneamento básico, escassez de água e de eletricidade (SANTOS, 2020b). Dessa forma, como garantir o direito ao lazer se nem o direito a uma vida digna lhe são garantidos? Como vivenciar o lazer em tempos de pandemia, se não é possível cumprir as 
recomendações da OMS? Como desenvolver o lazer em casa, com famílias numerosas e onde não é possível manter a distância interpessoal e a privacidade?

Percebe-se assim, que a pandemia evidencia e reforça as desigualdades sociais que se materializam no espaço (CARLOS, 2020). Amplia-se a esse entendimento, que esse espaço não é apenas o geográfico, mas envolve também o virtual.

No tocante ao tempo, a pandemia vem mostrando que a visão fragmentada trabalho e lazer está cada vez mais frágil e que os discursos que entendem o lazer em oposição ao trabalho, como propostos por Dumazedier (1979), Bacal (1988) e Cardozo (2014) devem ser rompidos. A compreensão do tempo, diante da imposição do home office, do ensino remoto, dos afazeres domésticos diários, das práticas de lazer, do cuidado com os filhos e a família, é revelada de forma não mais tão linear, padronizada e centralizada como outrora, $\mathrm{O}$ período pandêmico permite uma maior fluidez nas práticas sociais e traz à luz novas dinâmicas que deverão permanecer pós-pandemia da Covid-19. Ademais, segundo Santos (2020b), a humanidade viverá em pandemias intermitentes, tentando resolver com vacinas e confinamentos e caso isso prevaleça, esse tempo apresentará cada vez mais liquidez (BAUMAN, 1998).

Frente a esse cenário, a dicotomia entre trabalho-lazer, ócio-negócio ou qualquer outro tipo de oposição precisa ser repensada. Além disso, o lazer precisa ser compreendido como uma prática social complexa, e que lazer e o trabalho ambos são complementares, importante e essenciais para a totalidade da vida humana (WERNECK, 2008; VERA et al. 2013).

Isso posto, percebe-se como as categorias espaço e tempo estão sendo reconfiguradas frente à pandemia da Covid-19, considerada como um novo paradigma e com certeza continuarão interferindo nos direitos dos cidadãos e reconfigurando suas práticas sociais, dentre elas, o lazer. 


\section{Percurso Metodológico}

Este artigo é um recorte de uma pesquisa mais ampla que investiga a dinâmica do turismo no contexto da pandemia da COVID-19 no cenário do Rio Grande do Norte. Trata-se de pesquisa exploratória por meio de métodos propostos para levantamentos (GIL, 2010). Estuda fenômeno que se encontra em desenvolvimento e que se faz necessário estudo para a sua compreensão e acompanhamento de seus desdobramentos.

Foram utilizados para a análise dados primários e secundários. Os dados primários são oriundos de levantamento realizado no período de 8 a 30 de junho de 2020, alcançando o número de 520 respondentes. A coleta ocorreu por meio da ferramenta "Forms" do Google direcionada a pessoas residentes no RN e que tenham mais de 18 anos por comporem o grupo da população economicamente ativa. Antes da disponibilização do questionário para os possíveis respondentes, a pesquisa foi submetida, apreciada e aprovada pelo Comitê de Ética e Pesquisa da Universidade do Estado do Rio Grande do Norte.

Por se referir à investigação de amostragem não probabilística, a técnica de referência para o recrutamento das pessoas foi "bola de neve" (snowball sampling), onde os indivíduos iniciais selecionados, foram convidados pela rede de proximidade das pesquisadoras, que foram solicitados a convidar outros participantes próximos e assim por diante (BABBIE, 2004; VELASCO; DÍAZ DE RADA, 1997). Dessa forma, vale destacar que o link de acesso ao instrumento eletrônico de coleta de dados, foi disponibilizado livremente na rede de contato das pesquisadoras, bem como na página da Universidade do Estado do Rio Grande do Norte (UERN) por meio de publicação de notícia e nas redes sociais (Instagram e Facebook) do Curso de Turismo, da UERN, bem como de outras IES do RN, como a Universidade Federal do Rio Grande do Norte 
(UFRN) e o Instituto Federal do Rio Grande do Norte (IFRN), da Secretaria de Turismo do RN (SETUR/RN) e da Empresa de Promoção Turística do RN (EMPROTUR/RN).

Para subsidiar a análise utilizou-se de pesquisa bibliográfica para compreender os aspectos teóricos relacionados a pesquisas concernentes aos temas do direito, do lazer e risco de contaminação pelo coronavírus. Além disso, realizou-se pesquisa documental, analisando os decretos do governo do estado do $\mathrm{RN}$ e suas relações com o número de casos, óbitos e índice de isolamento social levantadas em fontes oficiais.

Ainda, para efeito de análise e comparação, foi empregada uma escala de risco ${ }^{6}$ de contrair a COVID-19 elaborada pela Texas Medical Association, organização americana que vem desenvolvendo pesquisas e estudos sobre a doença. A escala é composta por 37 atividades que são classificadas em uma pontuação de 1 a 10, as quais são sistematizadas entre pouco risco, médio-baixo, risco médio, médio-alto e risco alto. Cabe ressaltar que os especialistas da organização destacam que a escala de riscos só vale para as pessoas que estão seguindo as orientações da Organização Mundial da Saúde (OMS), como a utilização de máscaras, higiene das mãos e distanciamento social de 1,5 metros a 2 metros.

\section{Um Breve Panorama da Covid-19 no Rio Grande do Norte}

Ao se realizar uma análise considerando as relações da pandemia de COVID-19 e o lazer dos residentes do Rio Grande do Norte, faz-se importante destacar alguns aspectos que dizem respeito às estatísticas relacionadas à contaminação do novo coronavírus no $\mathrm{RN}$, pois essas informações auxiliam no entendimento de como o vírus se manifesta no estado e nas percepções de segurança e risco de contágio pelo novo coronavírus. 
O estado potiguar está situado no nordeste brasileiro, possui 167 municípios, abrangendo uma área total de 52.811,107 km² e uma população de 3.168 .027 habitantes. (IBGE, 2012). Os primeiros casos confirmados e o primeiro registro de óbito apareceram entre os dias 16 e 30 de março de 2020, cresceram bastante em abril e maio, se acentuando significativamente em junho, superando os 10 mil casos confirmados no início do mês de agosto de 2020. Quanto ao registro de óbitos, este apresenta, também, um crescimento, contudo, menos expressivo, se comparado ao crescimento no número de casos que foram se confirmando ao longo de junho.

No mês de julho, tanto a curva relativa ao número de casos confirmados, como de óbitos dão indícios de um arrefecimento que se confirma no mês de agosto. À título de exemplo, o aumento no número de casos confirmados entre o dia 19 de maio e 19 de junho foi de 12.556 novos casos, o que equivale a um percentual de $78,3 \%$, enquanto no mês seguinte (entre os dias 19 de junho e 19 de julho), o aumento foi de 27.918, representando em termos percentuais por $63,5 \%$, caindo substancialmente entre os dia 19 de julho e 19 de agosto que registrou um crescimento de 14.710 novos casos, o que corresponde em termos percentuais a um aumento de $25,1 \%$.

A mesma análise cabe para o aumento de 533 novos casos no número de óbitos entre os dias 19 de maio e 19 de junho, o que corresponde a um crescimento percentual de 76,9\% e no aumento de 892 óbitos entre os dias 19 de junho e 19 de julho, o que corresponde a um aumento percentual de 56,3\% e entre os dias 19 de julho e 19 de agosto com 541 casos de óbito registrados, correspondendo a um aumento percentual de $25,4 \%$. Tal fato coloca o RN entre os cinco estados brasileiros ${ }^{7}$ com inflexão no número de casos confirmados e também de óbitos, conforme informação noticiada pelo pesquisador

\footnotetext{
${ }^{7}$ Os demais estados brasileiros que sinalizam com inflexão no aumento de casos confirmados e óbitos são: AM, CE, PA e RJ.
}

licere, Belo Horizonte, v.23, n.3, set/2020. 
Iamarino (2020) no dia 24 de julho de 2020. Essa diminuição de casos proporciona uma sensação de segurança, não significam que a situação está controlada.

No gráfico 01 é possível observar toda essa análise, registrando-se o número de casos confirmados e óbitos no RN, acompanhados em intervalo de tempo de 30 dias, entre o dia 19 de março e 19 de agosto de 2020.

\section{Gráfico 1: Casos COVID-19 - confirmados e óbitos - RN.}

80000

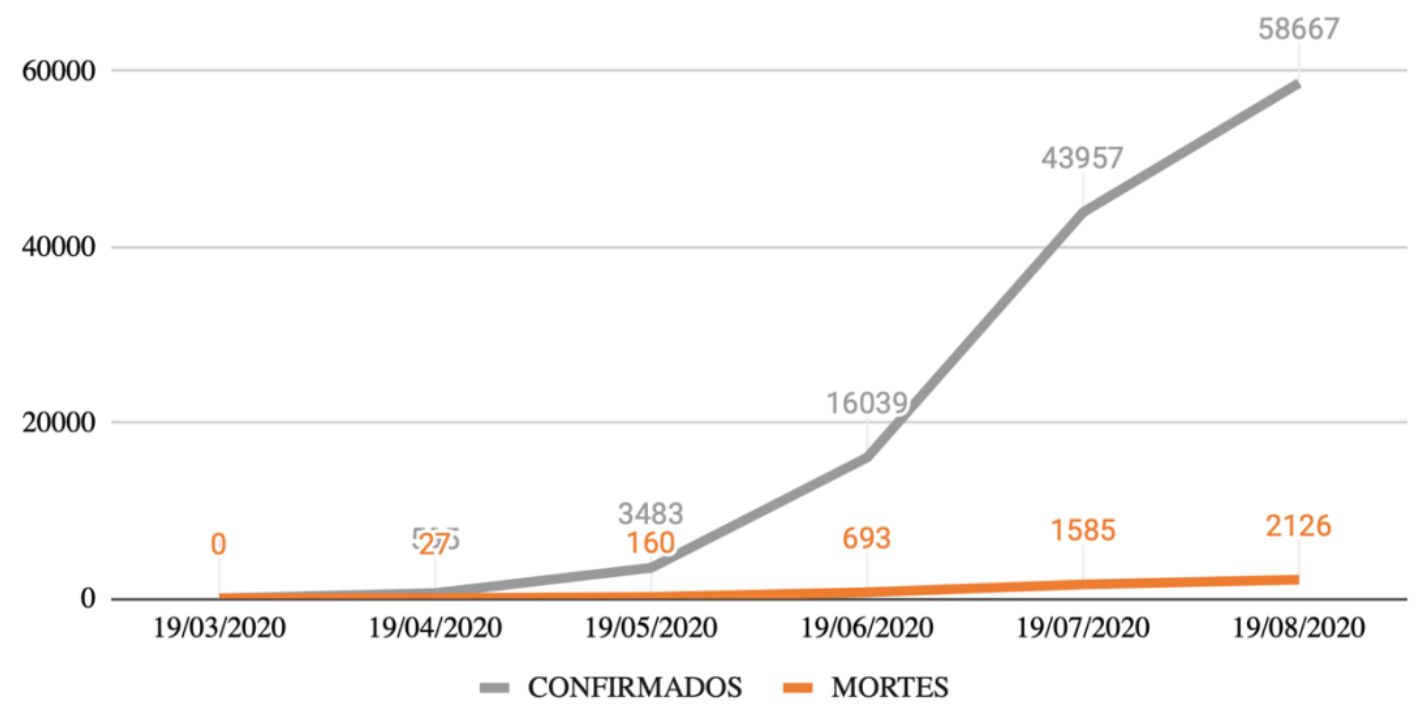

Fonte: Rio Grande do Norte (2020c).

Considerando o índice de isolamento social, o dia 22 de março de 2020, dois dias após o decreto de calamidade, o Rio Grande do Norte teve o maior índice de isolamento social $(57,7 \%)$, mantendo uma taxa superior a $50 \%$ até o início de abril.

Uma pesquisa do Instituto Datafolha (ZANINI, 2020) realizada entre $1^{\circ}$ e 3 de abril, com uma amostra de 1511 pessoas apontou que $76 \%$ das pessoas eram favoráveis à manutenção do distanciamento social para o controle da pandemia, mesmo que isso significasse prejuízos econômicos. O maior apoio ao distanciamento ocorreu no Nordeste com $81 \%$ e o menor no Sul com $70 \%$. 
A partir da segunda quinzena de abril observa-se uma queda do isolamento social, mantendo-se na faixa de $40 \%$ durante o restante do mês de abril, permanecendo nos meses de maio e junho e voltando a subir no mês subsequente, atingindo 50,4\% no dia 5 de julho de 2020.

Porém a partir dessa data, o índice vem diminuindo paulatinamente, alcançando o seu menor número no dia 3 de agosto de 2020, com 35,82\% desde o primeiro decreto estadual no enfrentamento da pandemia e tendo pequenas variações nas semanas seguintes, porém não atingindo $40 \%$ de taxa de isolamento, um índice considerado baixo para se evitar a propagação do vírus, conforme se observa no Gráfico 02.

Gráfico 2: Índice de isolamento social - RN.

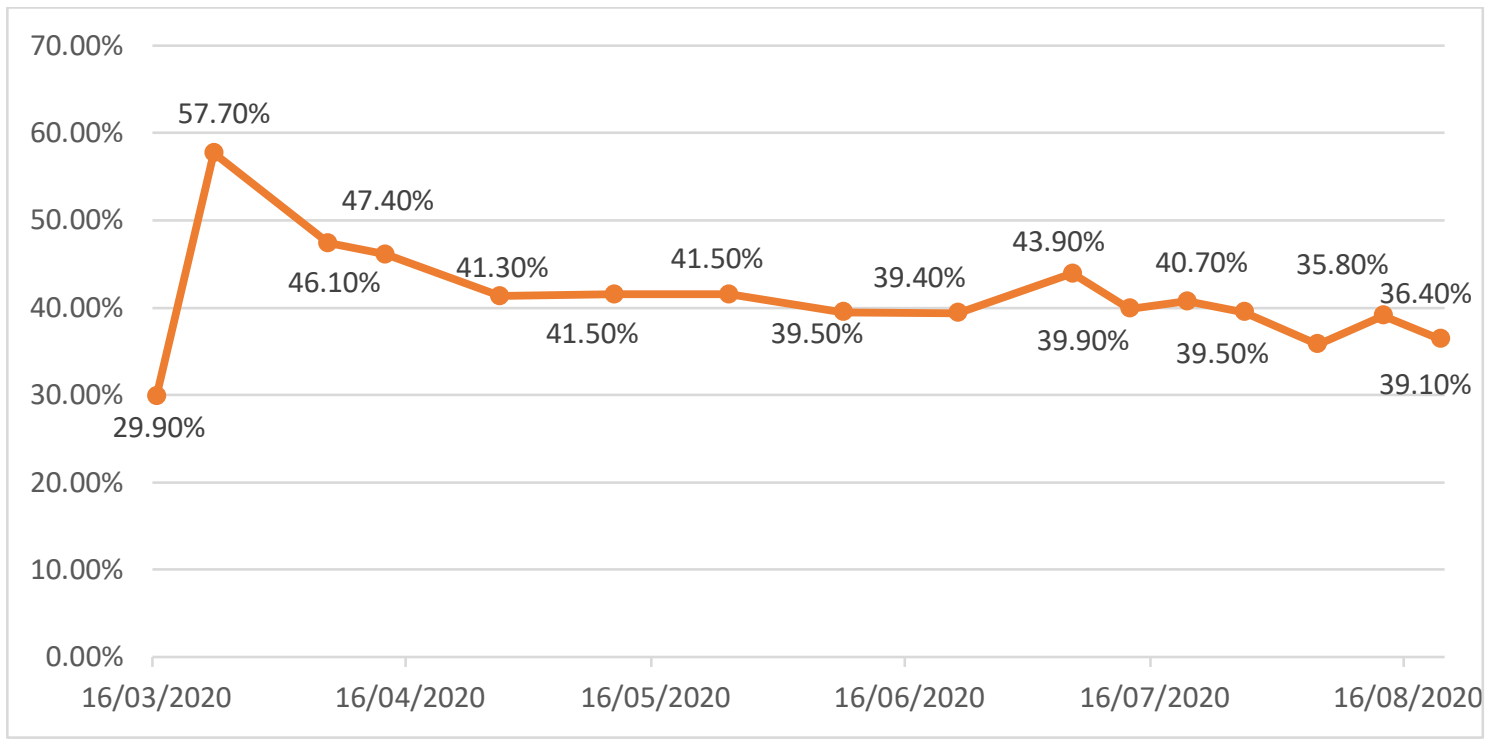

Fonte: Inloco (2020).

O resultado desse afrouxamento no isolamento social se deve, principalmente, ao Decreto n $^{\circ} 29815$ de 07 de julho de 2020, do Governo do Estado do RN, (RIO GRANDE DO NORTE, 2020d) que dispõe sobre as medidas de saúde e a política de isolamento social rígido para o enfrentamento do novo coronavírus (COVID-19) durante a retomada gradual responsável das atividades econômicas no âmbito do Rio Grande do Norte e dá outras providências.

licere, Belo Horizonte, v.23, n.3, set/2020. 
Depois de quase quatro meses de isolamento social, as pessoas sentem a necessidade de voltar "à normalidade", tendo a sensação que a reabertura da economia implica em controle e cura da pandemia, quando na verdade não significa isso. Mas é resultante de estudos que associam a diminuição do percentual de aumento de casos confirmados e de óbitos com o número de UTIs disponíveis e a taxa de transmissibilidade da doença. Isso implica dizer que as pessoas devem manter, se possível, o distanciamento e seguir todos os protocolos e medidas de segurança no combate ao covid-19.

Os reflexos desses dados são importantes para situar como o estado do Rio Grande se encontra frente a pandemia e como isso interfere na percepção de segurança e risco de contágio por covid-19, inclusive durante a realização de práticas de lazer. Essas questões serão aprofundadas na seção seguinte, como horizonte temporal o segundo semestre de 2020.

\section{Percepção de Segurança e Risco de Contágio por Covid-19 durantes as Vivências de}

\section{Lazer}

Tendo traçado um panorama da Covid-19 no Rio Grande do Norte, a investigação seguirá com o perfil socioeconômico da amostra formada por 520 respondentes, com idade superior a 18 anos e que residem em território potiguar. Ratifica-se que o levantamento foi realizado no período de 8 a 30 de junho de 2020, durante esse período o estado ainda estava sob o decreto n. 29.534, que recomendava o isolamento social.

Constatou-se que os respondentes em sua maioria são do sexo masculino (70\%), com uma maior expressão entre jovens adultos que compreende a faixa etária entre os 25 a $39 \operatorname{anos}(45,6 \%)$, apresentando nível de instrução pós-graduação completa $(46,2 \%)$, 
faixa de renda familiar que vai de mais de um até quatro salários mínimos $(31,5 \%)$ e tendo como ocupação mais citada, servidor público $(33,5 \%)$, conforme Tabela 1.

Tabela 1: Perfil socioeconômico dos respondentes da pesquisa.

\begin{tabular}{lll}
\hline Variável & Classificação & Porcentagem \\
\hline Faixa Etária & 18 a 24 anos & $13,7 \%$ \\
& 25 a 39 anos & $\mathbf{4 5 , 6 \%}$ \\
& 40 a 59 anos & $32,1 \%$ \\
\hline Sexo & 60 anos ou mais & $8,6 \%$ \\
\hline Nível de Escolaridade & Masculino & $\mathbf{7 0 \%}$ \\
& Feminino & $30 \%$ \\
& Ensino Fundamental Completo & $0,4 \%$ \\
& Ensino Médio Incompleto & $0,4 \%$ \\
& Ensino Médio Completo & $6,2 \%$ \\
& Ensino Superior Incompleto & $15,0 \%$ \\
& Ensino Superior Completo & $22,6 \%$ \\
& Pós-graduação Incompleta & $9,2 \%$ \\
& Pós-graduação Completa & $\mathbf{4 6 , 2 \%}$ \\
\hline Faixa de Renda Familiar & Sem Rendimento & $2,1 \%$ \\
& Até 1 salário mínimo & $7,5 \%$ \\
& Mais de 1 até 4 salários mínimos & $\mathbf{3 1 , 5 \%}$ \\
& Mais de 4 até 7 salários mínimos & $21,9 \%$ \\
& Mais de 7 até 10 salários mínimos & $14,7 \%$ \\
& Mais de 10 salários mínimos & $22,3 \%$ \\
\hline Ocupação & Empregado & $10,9 \%$ \\
& Desempregado & $7,3 \%$ \\
& Autônomo & $11,9 \%$ \\
& Profissional Liberal & $7,0 \%$ \\
& Servidor Público & $\mathbf{3 3 , 5 \%}$ \\
& Empresário & $5,5 \%$ \\
& Freelancer & $1,6 \%$ \\
& Estudante & $15,5 \%$ \\
& Aposentado & $4,9 \%$ \\
& Outros & $1,9 \%$ \\
\hline
\end{tabular}

Fonte: Dados da pesquisa, jun. 2020.

De acordo com dados do Instituto Brasileiro de Geografia e Estatística (2016), os indicadores estruturais do mercado de trabalho para pessoas com 16 anos ou mais de idade apontam que a população ocupada no Brasil encontra maior proporção na faixa etária dos 25 aos 39 anos, seguido de acima de 50 anos e 40 a 49 anos em porcentagens muito próximas. Logo, infere-se que a amostra alcançada com esta pesquisa, em sua maioria, é de pessoas que possuem ocupação e que estão inseridas no mercado de trabalho, as quais podem ser consumidoras em potencial de produtos e serviços de lazer, tais como: viagens, shows, cinema e games. 
Considerando especificamente o mercado turístico, segundo dados do Ministério do Turismo (MTur), as maiores porcentagens de pessoas que demonstram intenção de viajar possuem grau de escolaridade entre superior completo e pós-graduação, o que representa $78 \%$ da amostra desta pesquisa, denotando que a mesma é formada por turistas em potencial. Ainda de acordo com dados do MTur, os potenciais consumidores que mais manifestam desejo de viajar estão entre os que ganham de cinco a dez salários mínimos e aqueles que auferem acima de dez salários mínimos, o que pode representar nesta pesquisa um percentual acima da metade dos respondentes que estão entre aqueles que recebem de 4 até mais de dez salários mínimos. (FGV; MTUR, 2017).

Levando em consideração que neste momento de excepcionalidade, aspectos como disponibilidade de tempo e de recursos, que são condicionantes da demanda, não são suficientes para a realização de viagens devido ao isolamento social; a pesquisa investigou a percepção de segurança em realizar viagens novamente em horizonte temporal de curto prazo (jul-dez 2020), conforme entendimento do Plano de Retomada do Turismo, proposto pela Secretaria de Turismo do Rio Grande do Norte (SETUR) e Empresa Potiguar de Promoção Turística (EMPROTUR).

Para esta finalidade foram utilizadas questões que tiveram como referência a escala de Likert, escala psicométrica utilizada em pesquisas com o intuito de entender opiniões e atitudes dos respondentes em termos de gradação. Os níveis utilizados foram: discordo totalmente, discordo, indiferente, concordo e concordo totalmente. Para simplificar a análise textual, optou-se por somar os percentuais de discordância (discordo totalmente e discordo) e de concordância (concordo totalmente e concordo).

A pesquisa revelou que parcela majoritária dos respondentes discordam ou discordam totalmente em realizar algum tipo de viagem no segundo semestre de 2020 (gráfico 3). Ressaltando que a discordância aumenta à medida que aumenta a distância 
do possível deslocamento. Neste sentido, vale destacar que $67,1 \%$ dos entrevistados demonstraram discordar ou discordar totalmente em viajar para destinos locais ainda em 2020. Este percentual sobe para 70,5\% quando se referem a destinos regionais, sobe para $79,5 \%$ quando o destino é nacional e 80,8\% para destinos internacionais.

Seguindo a mesma lógica, o percentual de respondentes que indicaram concordância ou concordância total em realizar viagens em 2020 é maior quando se trata de destinos locais $(22 \%)$. Destes somente $5 \%$ concordam totalmente em realizar viagens no próprio RN. O percentual dos que concordam totalmente, cai para 3,7\%. quando o destino é regional, para $1,4 \%$ quando mencionado o destino é nacional e $2,5 \%$ para destinos internacionais.

\section{Gráfico 3: Segurança em realizar viagens de lazer no segundo semestre de} $2020(\%)$.

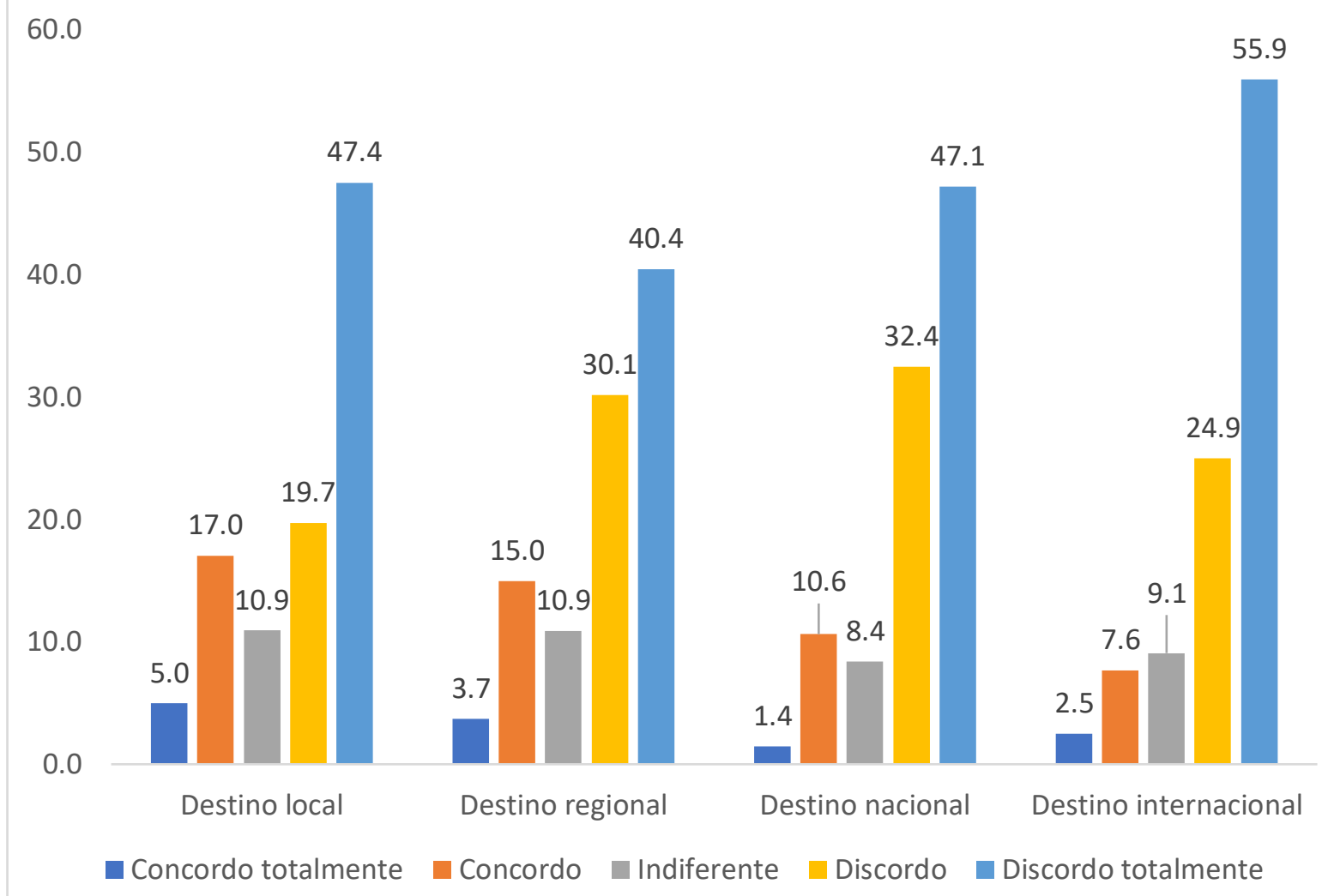

Fonte: Dados da pesquisa, jun. 2020.

Percebe-se assim, que ao pensar na viagem de lazer, os respondentes ainda se sentem inseguros em realizá-las no segundo semestre de 2020. O turismo é uma 
experiência sociocultural, tendo a necessidade do contato com o outro, e devido a isso, o risco de contágio é mais alto.

Cabe destacar que o entendimento de risco neste contexto de pandemia envolve ameaça e/ou vulnerabilidade à saúde humana, quando há a probabilidade de dano para o sujeito (ENAP, 2017). No caso do coronavírus, que abrange desde quadros assintomáticos até quadros respiratórios graves, e que podem chegar a letalidade, mas que, através de medidas de prevenção, tais como: manter o isolamento social, higienizar as mãos e utilizar álcool 70\%, que diminuem exponencialmente o perigo do contágio.

Se considerarmos a escala de risco de contrair a Covid-19 elaborada pela Texas Medical Association, o ato de viajar de avião é uma atividade de médio-alto risco e hospedar-se em um hotel por duas noites é médio-baixo, mesmo se forem seguidas todas orientações da OMS, caso contrário, o risco aumenta.

Desta maneira, o contexto atual exige adaptação e adequação de produtos, serviços, ambientes e empreendimentos para que, quando houver uma maior flexibilização do isolamento social e a retomada gradual das atividades turísticas, os turistas possam vivenciar experiências, não apenas dentro de suas condições orçamentárias ou de deslocamento, mas pricipalmente de forma que se sintam seguros para estarem nestes destinos.

Além disso, o investimento de tempo para educação e informação nesse momento é fundamental, não apenas para o trade turístico, mas também, para as pessoas como cidadãos, potenciais turistas, pois é um processo novo para todos e o poder público não terá estrutura organizacional para fiscalizar constantemente os serviços e empreendimentos, assim os verdadeiros "fiscais" serão os consumidores. No contexto contemporâneo, em que as avaliações online podem influenciar o processo decisório de compra, esse poderá ser considerado um critério para as futuras avaliações no que vem se 
denominando de "novo normal", a nova realidade que vem se delineando e com a qual todos terão que se adaptar e se reinventar para atender às exigências e necessidades de seus consumidores. E a implementação dessas práticas interferirá na percepção de segurança dos usuários desse tipo de serviço e na retomada dessas atividades.

A pesquisa investigou também a percepção de segurança em realizar 14 atividades ainda no segundo semestre de 2020, nas quais o lazer pode ser manifesto em suas mais variadas formas, a saber: frequentar parques de diversões ou parques temáticos; frequentar parques naturais, florestas, fazer caminhadas, esportes de natureza etc.; visitar teatros, galerias de arte, museus, monumentos etc.; ir à praia, rios, açudes, cachoeiras e lagoas; assistir a shows, concertos, festivais e espetáculos; visitar centros urbanos ou centros históricos; realizar refeições em restaurantes; ir para shopping centers; fazer compras em ruas comerciais/centros de comércio popular; sair à noite, dançar, frequentar boates, ir a bares e locais de entretenimento noturno; fazer city tours, passeio de buggy e visitas organizadas; assistir a eventos esportivos, ir a estádios e academias; utilizar serviços de alimentação por aplicativo, delivery e take way; frequentar locais religiosos, fazer peregrinações, participar em eventos religiosos.

Pode-se observar que dentre os equipamentos de lazer categorizados, incluem-se os específicos (criados com a finalidade de vivenciar o lazer) e não-específicos (podem ser utilizados para se vivenciar o lazer, mas não foram criados com essa finalidade); tanto de gestão pública quanto privada e do terceiro setor; com as mais variadas dimensões (pequeno, médio e grande porte); e com finalidades programáticas diversas (de acordo com interesse ou grupo/segmento específico) (MARCELLINO,1996; CAMARGO, 1992).

Além das 14 categorias descritas anteriormente, incluiu-se também duas variáveis que envolvem acesso para usufruir dessas práticas: utilizar transporte público; e utilizar 
serviços de transporte por aplicativo, como Uber, 99, blablacar etc. Ressalta-se que essas duas categorias foram inclusas por compreender que o acesso a determinados espaços e equipamentos de lazer requerem deslocamento, sendo necessário fazer uso de serviço de transportes, que podem ser canais de disseminação do vírus, em tempos de pandemia.

Para melhor análise dos resultados, foi realizada uma abordagem quantitativa para estabelecer o Ranking Médio (RM) que foi estruturada numa escala Likert de 5 pontos para mensurar o grau de segurança dos sujeitos em realizar as atividades mencionadas. Para o estabelecimento do RM, foi retirada a média ponderada do número de ocorrências e estabelecida uma escala de 5 pontos para cada graduação: 1 - Totalmente inseguro; 2 Inseguro; 3 - Indiferente; 4 - Seguro; 5 - Totalmente seguro. O RM foi obtido através da somatória da média ponderada das ocorrências nas graduações acima, dividida pela média aritmética do número de ocorrências, conforme exemplo abaixo (OLIVEIRA, 2005). Conforme exemplo de tabela a seguir:

Tabela 2: Segurança em realizar atividade.

\begin{tabular}{lcccccc}
\hline Atividade & \multicolumn{5}{c}{ Frequência de sujeitos } \\
\hline & 1 & 2 & 3 & 4 & 5 & RM \\
\cline { 2 - 7 } $\begin{array}{l}\text { Frequentar parques de diversões ou } \\
\text { parques temáticos }\end{array}$ & 237 & 212 & 41 & 21 & 9 & $\mathbf{1 , 8}$ \\
\hline
\end{tabular}

Exemplo do cálculo do RM (Ranking Médio):

Média Ponderada $=(237 \mathrm{x} 1)+(212 \times 2)+(41 \times 3)+(21 \times 4)+(9 \times 5)=913$

Logo $\mathrm{RM}=913 /(237+212+41+21+9)=\mathbf{1 , 8}$

Para efeito de análise, lê-se que quanto mais próximo de 1, maior a insegurança das pessoas em realizar as atividades mencionadas e quanto mais próximo de 5, maior a segurança dos respondentes.

Em linha geral, é possível constatar que os respondentes se encontram ainda bastante temerosos em realizar a imensa maioria das atividades no segundo semestre de 
2020. Das 16 variáveis mencionadas ao longo da pesquisa, 13 obtiveram RM igual ou inferior a 2,3 (ver Gráfico 03).

A atividade apontada pelos respondentes como a mais segura foi a utilização de serviços de alimentação por aplicativo, delivery e take way $(\mathrm{RM}=3,2)$; seguida de deslocamento para praias, rios, açudes, cachoeiras e lagoas com RM de 2,8 e; frequentar parques naturais, florestas, fazer caminhadas esportes de natureza etc. (2,3). Esse descritivo reforça a ideia de que as atividades mais procuradas no cenário gradual de retomada, estão ligadas àquelas realizadas em espaços abertos, em contato com elementos naturais, que implicam em menor movimentação de pessoas e é possível manter a distância recomendada pelos órgãos de saúde.

Ademais, segundo estudos realizados pela OMS/OPAS (2020), o risco de disseminação do vírus em ambientes com grande circulação de ar é quase nulo e com as devidas medidas de segurança - distanciamento social mínimo de 1,5m, uso de máscaras e álcool $70 \%$ - o risco de contágio diminui drasticamente.

Comparando esses resultados com a escala de risco de contrair a COVID-19 proposta pela Texas Medical Association, ir para uma praia é uma atividade de risco médio; fazer uma caminhada, correr ou andar de bicicleta com outras pessoas é médiobaixo; e adquirir a comida de restaurante em serviço de take way é baixo.

Já as atividades indicativas de maior temor em relação à contaminação, segundo os pesquisados, são aquelas sugestivas de aglomerações, muitas das quais realizadas em espaços fechados. Nesse sentido, as apontadas como mais temerosas estão relacionadas ao acompanhamento de shows, concertos, festivais e espetáculos $(1,6)$; saídas noturnas para dançar, frequentar boates, bares e espaços de entretenimento $(1,7)$; acompanhamento de eventos esportivos, frequentar a estádios e academias (1,8); frequentar parques de diversões e parques temáticos $(1,8)$, conforme gráfico 03 . 
Considerando a escala de risco de contrair a Covid-19 elaborada pela Texas Medical Association, todas essas atividades citadas pelos respondentes são de alto risco, ratificando o resultado encontrando junto aos pesquisados, onde a probabilidade de contágio é muito elevada.

Segundo pesquisas da OMS/OPAS (2020) há registros de surtos da doença em alguns ambientes fechados como restaurantes, boates, locais de culto ou ambientes de trabalho através da transmissão por gotículas muito pequenas de saliva (aerossóis) especialmente em recintos fechados, onde há espaços lotados e inadequadamente ventilados, onde as pessoas infectadas passam longos períodos com outras pessoas. Ademais, a transmissão dos coronavírus costuma ocorrer pelo contato pessoal com secreções contaminadas como: saliva, espirro; tosse; catarro; contato pessoal próximo, como toque ou aperto de mão; contato com objetos ou superfícies contaminadas, seguido de contato com a boca, nariz ou olhos. (RIO GRANDE DO NORTE, 2020e). Dessa forma, a insegurança dos entrevistados em frequentar tais espaços e realizar determinadas práticas sociais, encontra-se justificativa frente aos estudos já realizados.

As demais atividades foram percebidas de modo moderado, com destaque a ir a shoppings centers $(1,9)$; e visitar teatro, galerias de arte, museus, monumentos etc. $(1,9)$, conforme se observa no gráfico 03 . As mesmas são avaliadas como atividades de risco médio e médio-baixo, respectivamente, conforme a escala de risco da Texas Medical Association.

Cabe fazer ainda mais uma ponderação com relação aos resultados encontrados no gráfico 04, refere-se ao tocante à utilização de serviços de transportes: para os pesquisados, a utilização de transporte público assumiu um grau de segurança moderado, atingindo uma média de 1,8; já a utilização de serviços de transporte por aplicativo, como Uber, 99, blablacar etc., mostrou maior segurança, com média de 2,3. Esse resultado 
também pode ser explicado, porque no serviço de transporte por aplicativo não há aglomeração de pessoas, a sensação de risco é bem menor quando se pensa em transporte de uso coletivo.

\section{Gráfico 4 - Realização de atividades de lazer no segundo semestre de 2020 (Ranking Médio).}

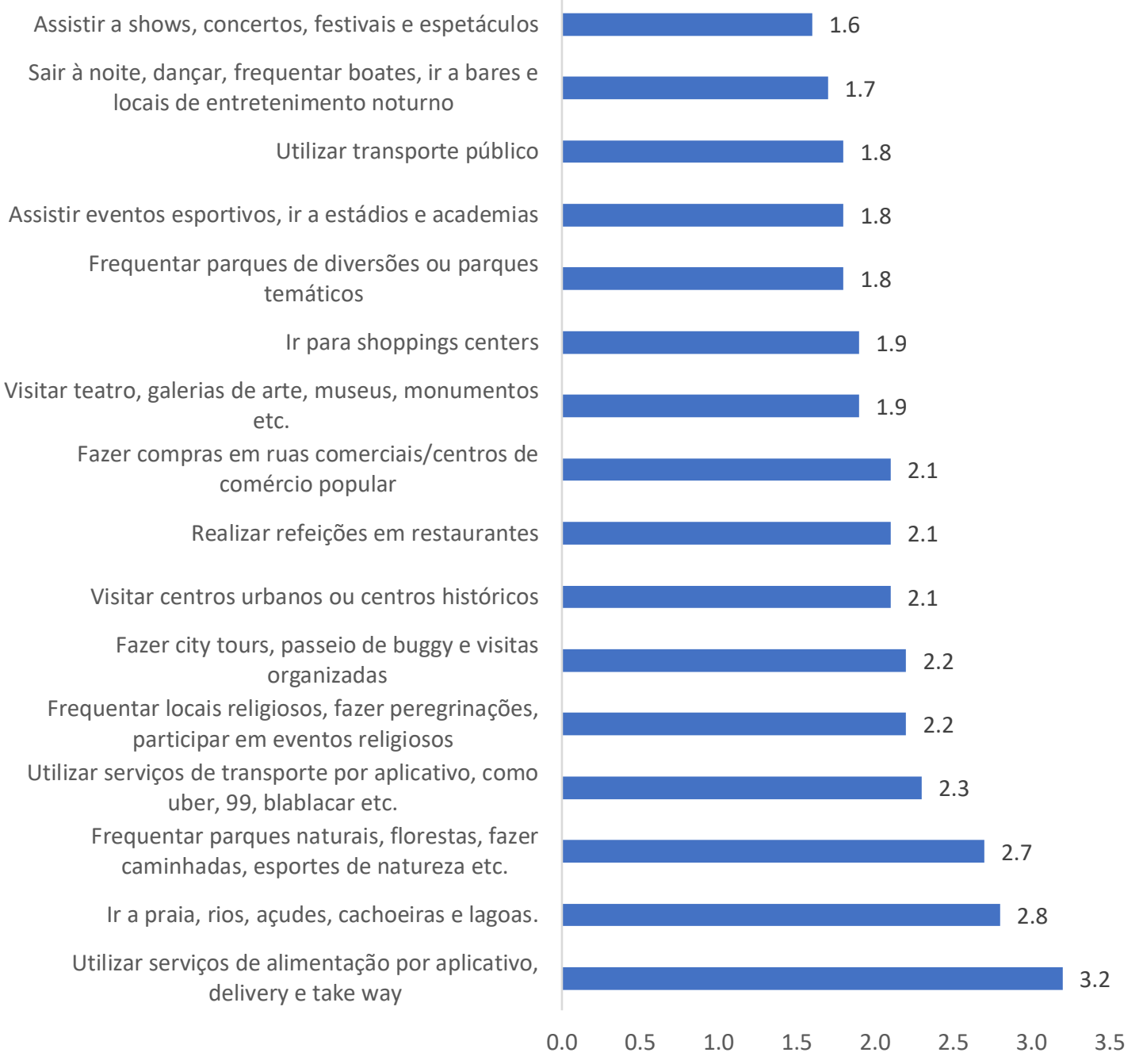

Fonte: Dados da pesquisa, jun. 2020.

Importante destacar ainda, que os resultados desta investigação expressam o entendimento atual sobre as diversas questões tratadas no decorrer da pesquisa, o que significa que se trata de uma pesquisa circunstancial, tendo em vista que as incertezas são postas em evidência nesse contexto de pandemia. Em uma suposta situação de controle 
total da contaminação em curto espaço de tempo, possibilitado por uma vacina, por exemplo, certamente esses resultados expressariam outros valores.

\section{Considerações Finais}

A discussão suscitada no artigo trouxe um breve panorama do cenário da pandemia da Covid-19 no Rio Grande do Norte, ratifica-se que os resultados constados são situacionais e, caso outros fatores surjam, as perspectivas podem ser ratificadas, refutadas ou alteradas, uma vez que a pandemia ainda não está controlada, o vírus sofre mudanças e já pode-se constatar uma segunda onda da doença em algumas cidades, como em Melborne (Austrália), Wuhan (China) e Barcelona (Espanha).

Apesar de um futuro de incertezas com relação a pandemia, a pesquisa representa um contributo para se pensar sobre o lazer no contexto local e refletir sobre outras realidades, principalmente na percepção de risco de contágio da Covid-19 durante as práticas de lazer.

Constatou-se que o período de isolamento social imposto pelos decretos estaduais mudou o cotidiano das pessoas, reconfigurando o espaço para o usufruto das vivências de lazer e rompendo com a compartimentação do tempo, onde as práticas sociais acontecem de forma mais fluída. Ademais, o risco de contrair o vírus fez com que as pessoas se sentissem mais seguras em desenvolver determinadas práticas de lazer em detrimentos a outras. Considerando as viagens, constatou-se que há uma forte insegurança em realizar tais práticas no segundo semestre de 2020 e, caso as mesmas venham a acontecer, serão realizadas majoritariamente em destinos locais, ou seja dentro do próprio estado. Acredita-se que enquanto a pandemia não esteja controlada, essa insegurança vá perdurar.

No tocante as demais práticas de lazer, as vivências nas quais os residentes do Rio Grande do Norte sentem-se mais seguros em praticar são aquelas que podem ser 
desenvolvidas em áreas naturais; já as menos seguras se remetem a áreas fechadas, com maior aglomeração de pessoas.

Percebe-se assim, a importância da governança no enfrentamento da pandemia, na gestão da saúde e em ações intersecretarias, como esporte, lazer, turismo e cultura. Além disso, agindo em parceria com a iniciativa privada e o terceiro setor na administração e monitoramento desses espaços, pois somente com planejamento e políticas adequadas será possível dirimir ou amenizar as consequências trazidas com a pandemia do SARSCoV-2.

Além disso, ratifica-se que o lazer enquanto direito social deve ser garantido pelo Estado em tempos pandêmicos ou não. Outrossim, antes de ser um direito constitucional, é uma necessidade humana e como tal fundamental para o bem-estar e qualidade de vida do indivíduo, em qualquer tempo, espaço ou contexto sociocultural.

Acredita-se que percepção de segurança e risco de contágio nos espaços e vivências de lazer estarão associadas ao processo de reabertura econômica, fiscalização e repercussão das medidas preventivas os protocolos de segurança atreladas ao número de casos da Covid-19, uma vez que essas práticas pressupõem interação sociocultural e as condições de segurança nos diversos espaços e equipamentos devem estar adequadas.

No caso do Rio Grande do Norte, a retomada está dividida em fases e frações que serão implementadas gradualmente em 35 dias, dentre os espaços e equipamentos a serem reabertos, têm-se: restaurantes; lanchonetes; food-parks; academias; shopping centers; hotéis; atrativos de livre acesso, como: praias, lagoas, rios, açudes e similares.

Porventura a pandemia perdure por mais tempo e as medidas não sejam devidamente seguidas, será necessário um novo endurecimento das medidas de distanciamento social e até um possível lockdown, influenciando ainda mais as vivências de lazer e no uso de determinados equipamentos e espaços, podendo ocasionar e agravar 
problemas de ordem social e mental, apontando um caminho possível para futuras investigações.

Isso posto, ressalta-se que o monitoramento da pandemia é fundamental para que haja maior reflexão sobre a realidade aqui discutida, uma vez que se trata de uma situação circunstancial, e a criação de uma vacina para a doença ou uma nova onda do vírus afetará diretamente nas práticas de lazer da população.

\section{REFERÊNCIAS}

AQUINO, E. M. L et al. Medidas de distanciamento social no controle da pandemia de COVID-19: potenciais impactos e desafios no Brasil. Ciência e Saúde Coletiva. Rio de Janeiro. V. 25 (suppl1), jun. 2020. Disponível em: https://www.scielosp.org/article/csc/2020.v25suppl1/2423-2446/pt/\#. Acesso em: 29 jul 2020.

BABBIE, Earl. The logic of sampling. In: The Practice of Social Research. 10. ed. Belmont: Wadsworth/Thompson Learning, 2004. p. 178-187.

BACAL, S. S. Lazer: teoria e pesquisa. São Paulo: Loyola, 1988.

BAUMAN, Zygman. O mal-estar da pós-modernidade. Rio de Janeiro: Zahar, 1998.

BRASIL. Constituição. Constituição da República Federativa do Brasil, 1988. Brasília: Senado Federal, Centro Gráfico, 1988. 292p.

CAMARGO, Luiz Otávio de Lima. O que é lazer? 3. ed. São Paulo: Brasiliense, 1992.

CANABARRO A, et al Data-Driven Study of the COVID-19 Pandemic via AgeStructured Modelling and Prediction of the Health System Failure in Brazil amid Diverse Intervention Strategies. MedRxiv, Yale, abr. 2020. Disponível em: https://www.medrxiv.org/content/10.1101/2020.04.03.20052498v2.article-metrics.

Acesso em: 01 jul. 2020.

CARDOZO, Juan Manoel Carreño. Poder e hegemonia na construção do conhecimento do lazer. In: ISAYAMA, Hélder Ferreira; OLIVEIRA, Marcus Aurelio Taborda.(org). Produção de conhecimento em Estudos do Lazer: paradoxos, limites e possibilidades. Belo Horizonte: Editora UFMG, 2014. p.13-29.

CARLOS, Ana Fani Alessandri. As faces da desigualdade socioespacial iluminadas pela crise da Covid-19. Grupo de estudos da teoria urbana crítica. Ensaios. São Paulo: Instituto de Estudos Avançados da Universidade de São Paulo, 2020.

DUMAZEDIER, Joffre. Sociologia empírica do lazer. São Paulo: Perspectiva, 1979. 
ENAP. Escola Nacional de Administração Pública. Módulo3. Risco sanitário, controle e monitoramento em vigilância sanitária. Brasília, 2017. Disponível em: https://portal.anvisa.gov.br/documents/33856/3428144/M\%C3\%B3dulo+3++Risco+sanit\%C3\%A1rio+controle+e+monitoramento+em+Vigil\%C3\%A2ncia+Sanit \%C3\%A1ria.pdf/5a72e9c7-b5d3-49ea-a3fa-24a3ed83e377. Acesso em: 07 jul. 2020.

FGV; MTUR. Fundação Getúlio Vargas; Ministério do Turismo. Sondagem do consumidor: intenção de viagem. Rio de Janeiro, 2017. Disponível em: http://www.dadosefatos.turismo.gov.br/sondagens-conjunturais/sondagem-doconsumidor-intenção-de-viagem.html. Acesso em: 30 de jul. 2020.

FIOCRUZ. Riscos biológicos. Disponível em: https://www.fiocruz.br/biosseguranca/Bis/lab_virtual/riscos_biologicos.html. Acesso em: 08 ago. 2020.

GIL, Antonio Carlos. Como elaborar projetos de pesquisa. 5. ed. São Paulo: Atlas, 2010 .

GOMES, Christianne Luce. Lazer: necessidade humana e dimensão da cultura. Revista Brasileira de Estudos do Lazer. Belo Horizonte, v. 1, n.1, p.3-20, jan./abr. 2014a.

El ocio y la recreación en las sociedades latinoamericanas actuales. Polis, Revista Latinoamericana, v.13, n.37, p. 363-384, 2014b.

IAMARINO, Átila. Atualizações e essa tal imunidade de rebanho. Vídeo Youtube. 24 jul. 2020. Disponível em: https://www.youtube.com/watch?v=KjFt7jPSJ2M. Acesso em: 25 jul. 2020.

IBGE. Instituto Brasileiro de Geografia e Estatística - IBGE. Censo demográfico 2010: resultados gerais da amostra. Rio de Janeiro, 2012.

Síntese de indicadores sociais: uma análise das condições de vida da população brasileira 2016. Rio de Janeiro, 2016. Disponível em: https://biblioteca.ibge.gov.br/visualizacao/livros/liv98965.pdf. Acesso em: 30 jul. 2020.

INLOCO. Índice de isolamento social RN. Disponível em: http://mapabrasileirodacovid.inloco.com.br/pt/. Acesso em: 08 ago.2020.

LARGHI, N. Com quarentena, venda de itens para exercícios em casa cresce até 10 vezes. Valor investe. São Paulo, 06 abr. 2020. Disponível em: https://valorinveste.globo.com/mercados/rendavariavel/empresas/noticia/2020/04/06/com-quarentena-venda-de-itens-para-exerciciosem-casa-cresce-ate-10-vezes.ghtml. Acesso em: 28 jul.2020

LINDNER, Julia. Ministério da Saúde declara estado de transmissão comunitária de coronavírus no país. Disponível em: http://saude.estadao.com.br/noticias/geral,ministerio-da-saude-declara-estado-detransmissao-comunitaria-de-coronavirus-em-todo-o-pais,70003242077. Acesso em: 14 abr. 2020. 
MARCELLINO, Nelson Carvalho. Estudos do lazer: uma introdução. Campinas: Autores Associados, 1996.

OLIVEIRA, Luciel Henrique. Exemplo de cálculo de Ranking Médio para Likert. Notas de Aula. Metodologia Científica e Técnicas de Pesquisa em Administração. Mestrado em Adm. e Desenvolvimento Organizacional. PPGA CNEC/FACECA: Varginha, 2005.

OPAS/OMS. Folha Informativa - COVID-19: doença causada pelo novo coronavírus. 2020.

Disponível

em: http://www.paho.org/bra/index.php?option=com_content\&view=article\&id=6101:covid 19\&Itemid=875. Acesso em: 21 ago. 2020.

PANORAMA Mobile Time/Opinion Box - Uso de Apps no Brasil revela que metade dos usuários de smartphone conversaram mais em vídeo e viram mais eventos online pelo smartphone durante o isolamento social. Disponível em: http://www.portaldailha.com.br/noticias/lernoticia.php?id=46816. Acesso em: 09 ago. 2020.

PIRES, Antônio. Direito Constitucional ao lazer: como anda o seu? JUSBRASIL. 2012. Disponível em: http://antoniopires.jusbrasil.com.br/artigos/121940598/direitoconstitucional-ao-lazer-como-anda-o-seu. Acesso em: 01 de jul. 2020.

RIO GRANDE DO NORTE. Decreto n. 29.534, de 19 de março de 2020. Diário Oficial do Rio Grande do Norte. Natal, RN, mar 2020a. Disponível em: https://diariooficial.rn.gov.br/dei/dorn3/docview.aspx?id_jor=00000001\&data=2020032 0\&id_doc=677886. Acesso em: 20 maio. 2020.

Decreto n. 29.524 de 17 de março de 2020. Diário Oficial do Rio Grande do Norte. Natal, mar. 2020b. Disponível em: http://diariooficial.rn.gov.br/dei/dorn3/docview.aspx?id_jor=00000001\&data=2020031 8\&id_doc=677489. Acesso em 28 jul. 2020

Decreto $N^{\circ} 29815$ de 07 de julho de 2020. Diário Oficial do Rio Grande do Norte. Natal, RN, jul 2020d. Disponível em: https://diariooficial.rn.gov.br/dei/dorn3/docview.aspx?id_jor=00000001\&data=2020071 4\&id_doc=688932. Acesso em: 09 ago.2020.

Óbitos confirmados por Dia. 19 de agosto de 2020d. Covid.lais.ufrn.br. Disponível em: https://covid.lais.ufrn.br/. Acesso em: 19 ago 2020

Secretaria de Estado da Saúde Pública do Rio Grande do Norte. Plano de contingência estadual para infecção humana pelo novo coronavírus. $5^{\mathrm{a}}$ versão. Jul 2020e. Disponível em: http://portalcovid19.saude.rn.gov.br/wpcontent/uploads/2020/04/Plano-Estadual-de-Contingencia.-V.5.2020.pdf. Acesso em: 08 ago. 2020.

SANTOS, C. A quarentena versus a liberdade de locomoção. Revista Consultor Jurídico. 30 abr. 2020. Disponível em http://www.conjur.com.br/2020-abr-30/ferreirasantos-quarentena-liberdade-locomocao. Acesso em: 29 jul. 2020a.

licere, Belo Horizonte, v.23, n.3, set/2020. 
SANTOS, Boaventura de Sousa. A Cruel Pedagogia do Vírus. Coimbra: Almedina, 2020 b.

SCHWARTZ, Gisele Maria; CAMPAGNA, Jossett. Lazer e interação humana no ambiente virtual. Motriz, Rio Claro, v.12, n.2, p.175-178, mai./ago. 2006.

VELASCO, H.; DÍAZ DE RADA A. La lógica de la investigación etnográfica. Un modelo de trabajo para etnógrafos de la escuela. Madrid: Trotta, 1997.

VERA, Fernando J, et al. Análisis territorial del turismo y planificación de destinos turísticos. 2 ed. Valência: Tirant Humanidades, 2013.

WERNECK, Christianne Luce Gomes. Lazer, trabalho e qualidade de vida. 2008. Disponível em: https://www.motricidade.com/index.php/repositorio-aberto/42gestao/1229-lazer-trabalho-e-qualidade-de-vida. Acesso em: 27 maio 2018.

ZANINI, F. Para 76\%, as pessoas devem ficar em casa, diz Datafolha. Brasileiro quer manter isolamento nos moldes atuais contra o coronavírus. Folha de São Paulo. São Paulo, 06 abr. 2020. Disponível em: https://www1.folha.uol.com.br/equilibrioesaude/2020/04/para-76-as-pessoas-devemficar-em-casa-diz-datafolha.shtml. Acesso em: 29 jul. 2020.

\section{Endereço dos/as Autores/as:}

Salete Gonçalves

Departamento de Turismo/UERN

Av. Prof. Antônio Campos - Pres. Costa e Silva

Mossoró - RN - 59610-210

Endereço eletrônico: saletegoncalves@uern.br

Rosa Maria Rodrigues Lopes

Departamento de Turismo/UERN

Av. Prof. Antônio Campos - Pres. Costa e Silva

Mossoró - RN - 59610-210

Endereço eletrônico: rosarodrigues@uern.br

Michele de Sousa

Departamento de Turismo/UERN

Av. Prof. Antônio Campos - Pres. Costa e Silva

Mossoró - RN - 59610-210

Endereço eletrônico: michelesousa@uern.br

Tatiana Gehlen Marodin

IFRN/Campus Cidade Alta

Av. Rio Branco, 743 - Cidade Alta

Natal - RN - 59025-003

Endereço eletrônico: tatianagehlen @ hotmail.com 